\title{
Studies on the Extract of the Straw of Sorghum arundinaceum and Its Formulation As An Oral Solid Dosage Form
}

\author{
${ }^{1,}$ Simbat O. Mohammed, ${ }^{1 *}$ Chukwuemeka. P. Azubuike, ${ }^{1,}$ Jimson O. Odulaja \\ 2, Abimbola Sowemimo. \\ ${ }^{I}$ Department of Pharmaceutics and Pharmaceutical Technology, Faculty of Pharmacy, University of Lagos, \\ P.M.B 12003 Lagos, Nigeria \\ ${ }^{2}$ Department of Pharmacognosy, Faculty of Pharmacy, University of Lagos, P.M.B 12003 Lagos, Nigeria
}

\begin{abstract}
The nutritional and medicinal values of the straw of Sorghum arundinaceum were investigated and the freeze-dried extract of the straw was formulated as capsules. The mineral content and proximate analyses of the straw were determined. Phytochemical groups in the extract were identified. The polyphenolic contents were determined using ultraviolet spectroscopy. Standard methods were adopted to determine the physical properties of the extract as well as the quality of the formulated capsules. Mineral content analysis showed that the extract contains the following minerals: potassium $(13.24 \mathrm{mg} / \mathrm{g})$, calcium $(35.57 \mathrm{mg} / \mathrm{g})$, magnesium $(19.68 \mathrm{mg} / \mathrm{g})$, sodium $(8.64 \mathrm{mg} / \mathrm{g})$, iron $(14.49 \mathrm{mg} / \mathrm{g})$, manganese $(15.45 \mathrm{mg} / \mathrm{g})$, zinc $(7.35 \mathrm{mg} / \mathrm{g})$ and copper $(0.75 \mathrm{mg} / \mathrm{g})$. Proximate analysis revealed $4.65 \%$ moisture, $0.04 \%$ protein, $4.70 \%$ total ash, $38.25 \%$ crude fibre, $11.00 \%$ total fat and $41.37 \%$ total carbohydrate. The phytochemical groups identified include alkaloids, anthraquinones, cardiac glycosides, flavonoids, saponins, sugars, and tannins. Polyphenolic content analysis also revealed the following: $276 \mathrm{mg} / \mathrm{g}$ total flavonoids, $163 \mathrm{mg} / \mathrm{g}$ total proanthocyanidins, and $90 \mathrm{mg} / \mathrm{g}$ total phenolic acids. The extract has a dark-red colour, a bitter taste, a pungent odour and a gritty feel. Most of the particles had a diameter of less than or equal to $0.422 \mathrm{~mm}$ and they had a Carr's index of $11.72 \%$ and a Hausner ratio of 1.13. The formulated capsules passed weight uniformity and disintegration tests. These results show the nutritional and medicinal value of the straw of S. arundinaceum and also justified the formulation of the extract into capsules.
\end{abstract}

Keywords: Sorghum arundinaceum, mineral content, proximate analysis, phytochemicals, polyphenols.

\section{Introduction}

Recent advances in the fields of nutrition, medicine and technology have encouraged researchers to probe for dietary as well as health benefits that can be derived from plants and animals eaten as foods (nutraceuticals). Nutraceuticals have the potential to play a role in healthy eating as well as contribute to the prevention and treatment of diseases [1].

Sorghum arundinaceum (Desv.) Stapf also known as common wild sorghum is a tropical grass of African origin. Its straw is eaten in time of scarcity as famine food, brewed for beer, and consumed for leisure and also used as a forage crop for many grazing animals [2]. It is used ethnomedicinally in management of respiratory disorders, convulsions, measles, metrorrhagia and cholera [3]. The use of this plant for these purposes has been passed from one generation to the next without to a large extent the proper scientific knowledge of the actual components responsible for its medicinal properties and its formulation into an acceptable dosage form. This present study was aimed at investigating the substances which might be responsible for the erstwhile reported, as well as unknown potential nutritional and medicinal benefits of the plant. The formulation of the extract of the straw as a solid dosage form was also carried out.

\subsection{Plant materials}

\section{Materials And Methods}

Bunches of the dried straw of S. arundinaceum were procured from Ondo, Ondo State, Nigeria. They were identified at the Herbarium of the Department of Botany, University of Lagos, Nigeria and the voucher specimen (LUH 1429A) was deposited in the same herbarium for future reference. Bunches of the dried straw were subjected to size reduction to a coarse powder by using a cutter mill. A vibrator sieve shaker was used to separate the straw into different size fractions. $50 \mathrm{~g}$ of the milled straw with the smallest particle size was extracted with $500 \mathrm{ml}$ of distilled water at $100^{\circ} \mathrm{C}$ for 30 minutes in a water bath. The resulting decoction was made to cool to $28^{\circ} \mathrm{C}$ and then filtered with a muslin cloth. T The filtrate was stored in an air tight, light 
impervious bottle and frozen at $4^{\circ} \mathrm{C}$.. It was lyophilized to obtain a concentrated dry extract which was stored in an air tight, light impervious bottle.

\subsection{Chemical analysis}

Proximate analysis, including the moisture, crude protein ( $\mathrm{N} \times 6.25)$, total ash and total fat, were performed according to AOAC [4] procedure. Total carbohydrates, including fibre, were calculated by difference. Minerals were determined by atomic absorption spectrophotometer (Perkin Elmer, Waltham, MA, U.S.A) AOAC [4].

\subsection{Phytochemical investigation}

Methods as recommended by Sofowora [5] were adopted. The phytochemicals determined include alkaloids, free and combined anthraquinones, cardiac glycosides with steroidal nucleus and steroidal ring, flavonoids, saponins, sugars and reducing sugars, and hydrolysable and condensed tannins (proanthocyanidins). Total flavonoid content of the extract was estimated using the method of Miliauskas et al., [6] and was calculated as quercetin equivalent (QE) in $\mathrm{mg} / \mathrm{g}$ using equation 1 obtained from the calibration curve (Fig 1). $\mathrm{y}=3.146 \mathrm{x}+0.032, \mathrm{R}^{2}=0.961$ inmg/ml

where $\mathrm{y}=$ mean of absorbance obtained for the extract, $\mathrm{x}=$ concentration of extract

The total phenolic content of the extract was determined by the modified Folin-Ciocalteau method [7] and was expressed as mg/g gallic acid equivalent (GAE) using equation 2 obtained from the calibration curve (Fig 2) $\mathrm{y}=18.60 \mathrm{x}+0.225, \mathrm{R}^{2}=0.959$

The procedure reported by Sun et al. [8] was used to determine the total proanthocyanidin content of the straw and was expressed as catechin equivalent (CE) in $\mathrm{mg} / \mathrm{g}$ using equation 3 obtained from the calibration curve (Fig 3)

$y=1.656 x+0.061, R^{2}=0.958$

\subsection{Evaluation of some physical properties of extract}

Organoleptic properties of the extract were determined by observing the colour, taste, odour and texture of the extract. Particle size distribution was estimated using the method recommended by the United States Pharmacopoeia [9]. For the determination of the bulk and tapped densities, the methods employed in an earlier study were adopted [10]. Carr's index [11] and Hausner ratio [12] for the sample were calculated from bulk and tapped densities using Equations (4) and (5), respectively.

$$
\begin{gathered}
\text { Carr's Index }=\frac{D_{\text {tap }}-D_{\text {bulk }}}{D_{\text {tap }}} \times 100 \\
\text { Hausner Ratio }=\frac{D_{\text {tap }}}{D_{\text {bulk }}} \quad \ldots . .
\end{gathered}
$$

\subsection{Formulation of extracts as capsules}

$2.16 \mathrm{~g}$ of lactose and $27 \mathrm{~g}$ of the extract were individually weighed. The components were then mixed by geometric dilution in a glass mortar to effect proper mixing. $270 \mathrm{mg}$ of the mixture was then accurately weighed and hand-filled into the body of an empty hard gelatin capsule. 100 of such capsules were filled such that each capsule contained $250 \mathrm{mg}$ of the extract and $20 \mathrm{mg}$ of the diluent.

\subsection{Evaluation of the formulated product}

Capsules were tested for weight variation following the official method of USP32/NF27 in general chapter part <2091>, weight variation of dietary supplement. Capsules were also tested for disintegration following the official method of USP32/NF27 in general chapter part <2040>, disintegration and dissolution of dietary supplements [13].

\section{Results}

The results of the mineral content and proximate analysis are shown in Tables 1 and 2 respectively. The result of the phytochemical and polyphenolic composition of Sorghum arundinaceum are shown in Tables 3 and 4. Organoleptic properties showed the extract of Sorghum arundinaceum to be reddish-brown in colour, had a pungent odour, bitter taste, and a gritty feel while the physical properties evaluated showed that it had bulk and tapped densities of $0.369 \mathrm{~g} / \mathrm{ml}$ and $0.418 \mathrm{~g} / \mathrm{ml}$ respectively while the Carr's index and Hausner ratio were 
$11.72 \%$ and 1.13 respectively. The result obtained for percentage particle size distribution of the extract of the straw is shown in Fig 4.The results of the evaluation of the formulated product showed the weight uniformity of $367.61 \mathrm{mg}$ while disintegration test showed that the capsule shells started to disintegrate and release their contents approximately $56 \mathrm{~s}$.

\section{Discussion}

The mineral content analysis of the extract (Table 1) showed that calcium was the most abundant mineral present in the straw while copper was the least abundant. The mineral contents values differ from those of Sorghum sudanense [14] and Southern African sorghum varieties reported by Ng'uni et al. [15] The differences in the mineral content analysis values could be attributed to various factors such as the nature of the soil on which the plants were grown, differences in genetic make-up of the test plants, maturity of plant at time of harvest, climatic factors such as exposure to sunlight, and choice of method of analysis [16]. The recommended daily intake of iron is $18 \mathrm{mg}$, except in individuals who require a special high intake such as pregnant women and anaemic patients [17]. The results obtained for the proximate analysis (Table 2) revealed that the straw contained carbohydrates (41.365\%) and crude fibre (38.25\%). Carbohydrates are good source of energy while crude fibre helps to normalize bowel movement, and increases stool bulk, preventing constipation, diverticulosis and haemorrhoids [18]. The total ash (4.70\%) which is low implies that the extract has a good organic content and fairly low inorganic component. The moisture content is low (4.65\%). Low moisture content in foods is an index of quality, stability and good shelf life. The total fat and crude protein content in the straw are low. Lack of adequate protein in human diet can cause growth failure, loss of muscle mass, decreased immunity, weakening of the heart. Hence high consumption of the straw without supplementing with other sources of protein might lead to a deficiency of protein. All the phytochemicals tested for were present except for a class of cardiac glycosides known as 'cardenolides'. The study went further to probe for some specific phytochemicals within broad groups. The various phytochemicals present as well as their reported physiologic properties may impact upon this extract a wide range of possible medicinal properties. Some of the activities attributed to these classes of phytochemicals include anti-allergic, anti-cancer, antioxidant, anti-inflammatory and anti-viral for flavonoids, hallucinogenic, narcotic, and analgesic for alkaloids, [19] anti-obesity, anti-cancer, antifungal, anti-inflammatory and antioxidant properties for saponins [20] and reduced risk of coronary heart disease for proanthocyanidins [21]. The other phytochemicals present in the straw are anthraquinones which possess laxative properties [22] and cardiac glycosides which are useful in the treatment of cardiac failure and cardiac arrhythmias. The presence of these bioactive compounds in the straw gives an indication that the plant may possess some of the physiologic and medicinal activities attributed to these compounds.

The total flavonoid content of the extract of S. arundinaceum (Table 3) shows that the extract contains polyphenolics which have health benefits. Epidemiological studies have repeatedly shown an inverse association between the risk of chronic human diseases and the consumption of polyphenolic rich diet [23]. The epidemiological studies and associated meta-analyses strongly suggested that long term consumption of diets rich in plant polyphenols offered some protection against development of cancers, cardiovascular diseases, diabetes, osteoporosis and neurodegenerative diseases [24].The extract of S. arundinaceum had a pungent odour, bitter taste, and a gritty feel. These features give an evidence of the unpalatable and unattractive nature of the extract. There is the need to mask or conceal these features by the addition of suitable excipients or by encapsulation. The histogram (Fig 4) representing population distribution of the particles of the extract of Sorghum arundinaceum shows that the distribution of the extract particle size population is skewed to the left meaning that the extract population contains a larger proportion of smaller sized particles than larger sized particles. The particle size distribution of an active substance can significantly influence its manufacturability, stability and bioavailability. Powders with a wide particle size distribution do not blend evenly and this can lead to segregation during handling. Such powders also have different flow and packing properties which alters the volumes of powder during tabletting or encapsulation. Since the particles of the extract of the straw do not have a wide particle size distribution range, it is expected that there would be no problems during formulation of the extract as solid dosage form. The flowability of a powder is of critical importance in the production of capsule dosage forms in terms of the need for reproducible filling of capsules which improves weight uniformity and allows capsules to be produced with more consistent physicomechanical properties as well as the need for uniform packing and a constant volume-to-mass ratio which maintains capsule weight uniformity. The data for bulk and tap densities as well as Carr's Index and Hausner ratio confirmed that the extract has a good flow character as correlated with the scale of flowability [12].Weight variation of these capsules ranged from $99.92 \%$ to $100.10 \%$ of average weight. None of the capsules was out of the range of $90-110 \%$ average weight (USP32/ NF27 criteria) [17].The disintegration test carried out on the capsules showed that the capsule shells started to disintegrate from 56 seconds and capsule shells and its content disintegrated and dissolved completely in the immersion fluid in $21 \mathrm{~min}$. It is specified that the disintegration time of dietary supplements should not exceed 
$30 \mathrm{~min}$. This may be attributed to a case in which the extract has a hydrophilic character. Complete dissolution may also have been aided by the diluent used as lactose is a soluble diluent which imparts a hydrophilic character on substances to which it is added. This can have a significant effect on the bioavailability of the active as it may give a higher blood level of the drug.

Figures and Tables Figures

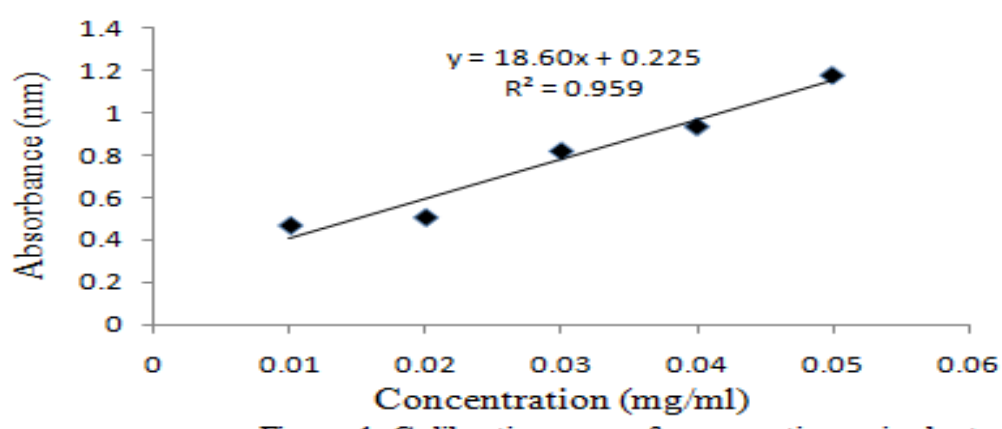

Figure 1. Calibration curve for quercetin equivalent

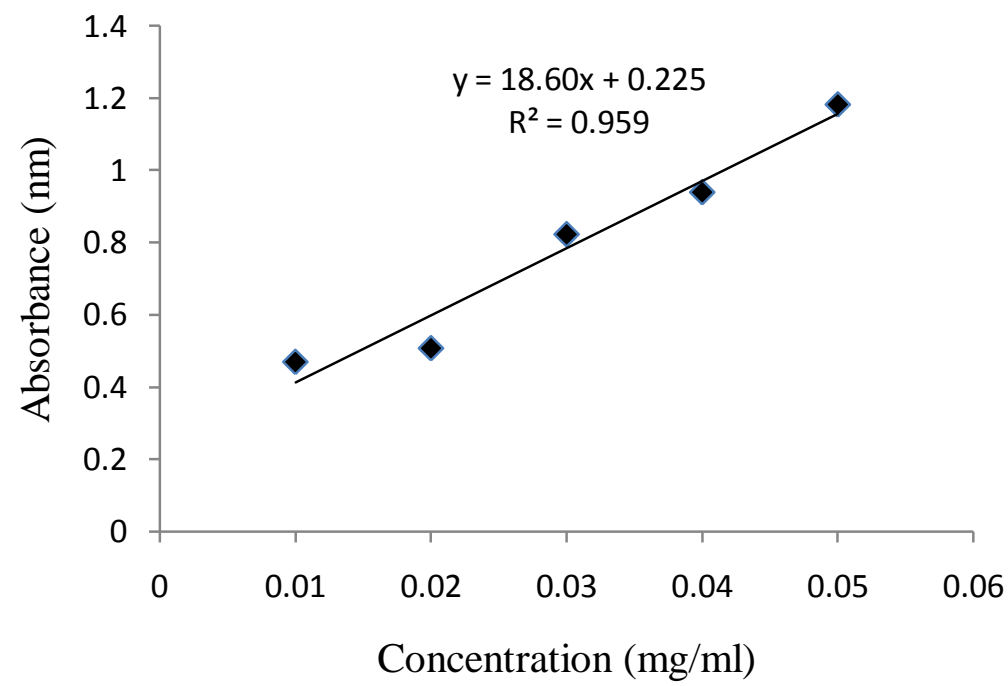

Figure 2. Calibration curve for gallic acid equivalent

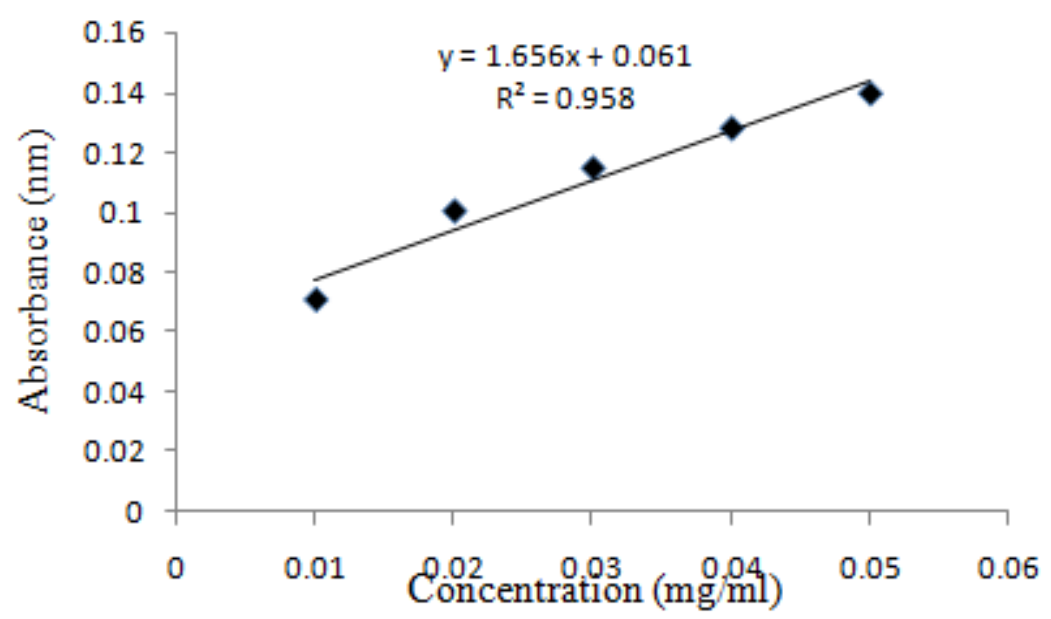

Figure 3. Calibration curve for catechin equivalent 


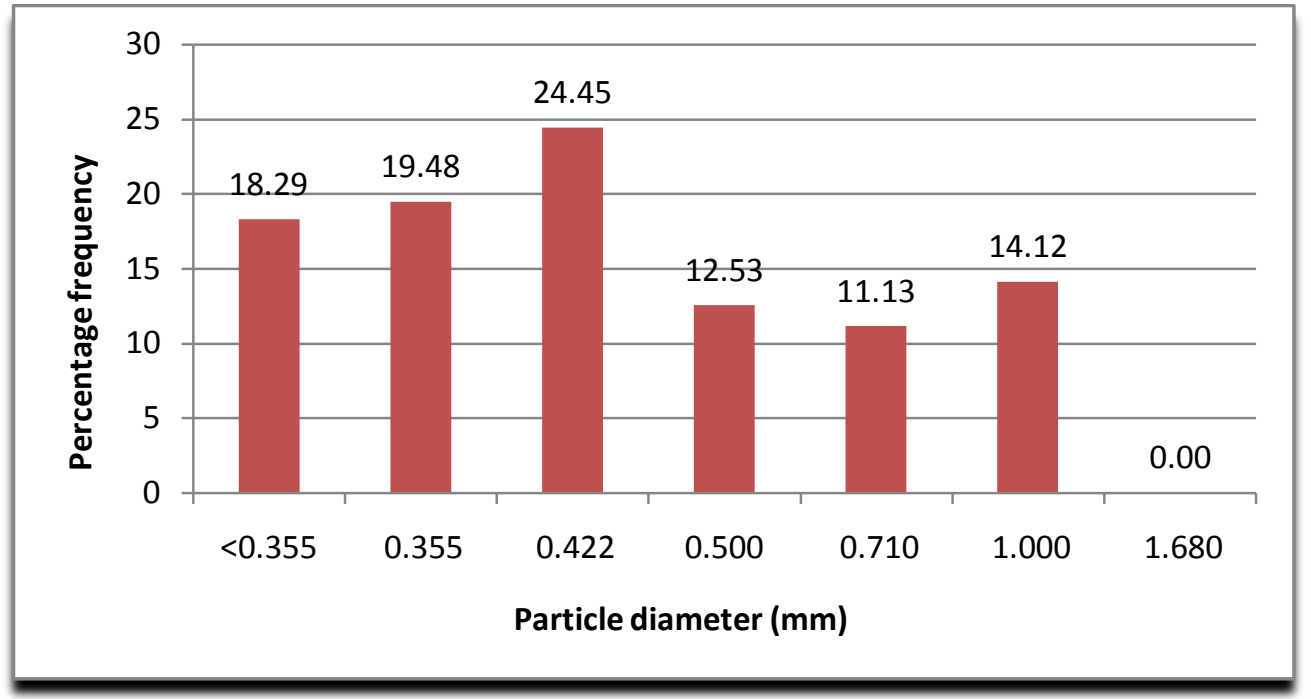

Figure 4. Histogram representing population distribution of the particles of the extract of the straw of Sorghum arundinaceum.

Tables

Table 1 Mineral composition of the straw of Sorghum arundinaceum

\begin{tabular}{cc}
\hline Mineral & Concentration $(\mathbf{m g} / \mathbf{g})$ in straw \\
\hline Potassium & $13.248 \pm 0.824$ \\
Magnesium & $19.676 \pm 0.534$ \\
Calcium & $35.567 \pm 0.420$ \\
Sodium & $8.639 \pm 0.010$ \\
Iron & $14.485 \pm 0.322$ \\
Manganese & $15.454 \pm 0.432$ \\
Zinc & $7.352 \pm 0.006$ \\
Copper & $0.795 \pm .0003$ \\
\hline
\end{tabular}

Table 2. Proximate composition of the straw of Sorghum arundinaceum

\begin{tabular}{lc}
\hline Dietary nutrient & Percentage composition in straw (\%) \\
\hline Moisture content & $4.65 \pm 0.14$ \\
Crude protein & $0.04 \pm 0.00$ \\
Total ash & $4.70 \pm 0.16$ \\
Crude fibre & $38.25 \pm 0.61$ \\
Total fat & $11.00 \pm 1.60$ \\
Total carbohydrate & $41.37 \pm 1.51$ \\
\hline
\end{tabular}

Table 3. Phytochemical composition of the straw of Sorghum arundinaceum

\begin{tabular}{lc}
\hline \multicolumn{1}{c}{ Phytochemical } & Present/ Absent \\
\hline Alkaloids & +++ \\
Anthraquinones & + \\
Free & ++ \\
Combined & \\
Cardiac glycosides & + \\
steroidal ring & ++ \\
steroidal nucleus & - \\
Cardenolides & +++ \\
Flavonoids & +++ \\
\hline with phenolic rings & ++ \\
\hline
\end{tabular}


$=$ absent $,+=\operatorname{present}($ small $),++=\operatorname{present}($ medium $),+++$ present(high $)$

Table 4. Polyphenolic composition of the extract of the straw

\begin{tabular}{lc}
\hline \multicolumn{1}{c}{ Polyphenols } & Concentration (mg/g) \\
\hline Total flavonoids (QE) & $276 \pm 9$ \\
Total phenolic acids (GAE) & $90 \pm 3$ \\
Total proanthocyanidins(CE) & $163 \pm 6$ \\
\hline
\end{tabular}

\section{Conclusion}

The results obtained in this study showed that the straw of Sorghum arundinaceum contains nutrients which are vital for maintaining good health as well as phytochemical groups which have various physiologic and medicinal benefits. This preliminary study also indicated that the extract has properties which enable it to be formulated into an acceptable capsule dosage form. Detailed analysis to ascertain the stability and suitability of the formulated product for human consumption will be subject of further study.

\section{References}

[1] S. Chaturvedi, P.K. Sharma, V. K, Garg,. and M. Bansal, Role of nutraceuticals in health promotion, International Journal of PharmTech Research 3(1), 2011, 442-448.

[2] J.R.N. Taylor, T..J. Schober' and S.R. Bean Novel food and non-food uses for sorghum and millets, Journal of Cereal Science, 44(3), 2006, 252-271.

[3] B.C. Ndukwu and N.B. Ben-Nwadibia. Ethnomedicinal aspects of plants used as spices and condiments in the Niger delta area of Nigeria,_Ethnobotanical Leaflets, 1, 2005, Article 10.

[4] AOAC Official Methods of Analysis. 15th edition. (Association of Official Analytical Chemists, Washington, DC, USA.) 1990

[5] A. Sofowora Phytochemical screening. in: Medicinal Plants and Traditional medicine in Africa. (Wiley, New York 1982). 142146.

[6] G. Miliauskas, P.R. Venskutonis and T.A. van Beek, Screening of radical scavenging activity of some medicinal and aromatic plant extracts. Food Chemistry, 85(2), 2004, 231-237.

[7] Wolfe K., Wu X, Liu RH. Antioxidant activity of apple peels. J. Agric. Food Chem., 51, 2003, 609-614

[8] J.S. Sun, Y.W. Tsuang, I.J. Chen, W.C. Huang Y.S. Hang and F.J. Lu. An ultra weak chemiluminescence study on oxidative stress in rabbits following acute thermal injury. Burns, 24, 1998, 225-231.

[9] USP, United States Pharmacopeia.. 27th Edition. (Rockville, Md.: United States Pharmacopeial Convention, 2004).

[10] C.P. Azubuike, H. Rodrı'guez, A.O. Okhamafe and R.D. Rogers, Physicochemical properties of maize cob cellulose powders reconstituted from ionic liquid solution. Cellulose 19, 2012; 425-33.

[11] R.L. Carr Jr, Evaluating flow properties of solids. Chem Eng, 72, 1965, 163-8.

[12] H.H. Hausner, Friction conditions in a mass of metal powders. Int J Powd Metall, 3, 1967, 7-13.

[13] The United States Pharmacopeial Convention, The United States Pharmacopeia/National Formulary. USP32/NF27. (Rockville, MD, USA. (2009) 782-786.

[14] J.A. Duke, Sorghum sudanense (Piper) Stapf. Handbook of Energy Crops. Centre for New Crops and Plant Products, Purdue University, Lafayette, IN. 1983

[15] D. Ng'uni, M. Geleta, E. Johansson, M. Fatih and T. Bryngelsson, Characterization of the Southern African sorghum varieties for mineral contents: Prospects for breeding for grain mineral dense lines African Journal of Food Science; 5(7), 2011,436 - 445

[16] Foster A, Malhi SS. Influence of Seeding Date and Growing Season Conditions on Forage Yield and Quality of Four Annual Crops in Northeastern Saskatchewan. Communications in Soil Science and Plant Analysis, 2012, doi: 121128063041001

[17] S.B. Goldhaber, Trace element risk assessment: essentiality vs. toxicity. Regulatory Toxicology and Pharmacology 38, 2003, $232-242$

[18] M.A. Eastwood, J.R. Kirkpatrick, W.D. Mitchell, A. Bone and T. Hamilton, Effects of Dietary Supplements of Wheat Bran and Cellulose on Faeces and Bowel Function_British Medical Journal , 4, 1973, 392-394

[19] J. Mann, R.S. Davidson, J.B. Hobbs, D.V. Banthorpe and J.B. Harborne, Natural Products: their chemistry and biological significance. (Essex: Longman Group1994)

[20] I. Hussain, R. Ullah, R. Ullah, M. Khurram, N. Ullah, A. F. Baseer, M. Khan, M. Khattak, M. Zahoor, J. Khan and N. Khan. Phytochemical analysis of selected medicinal plants African Journal of Biotechnology 10 (38), 2011, 7487-7492

[21] R. Corder, W. Mullen, N.Q. Khan, S.C. Marks, E.G. Wood, M.J. Carrier and A. Crozier. Oenology: Red wine procyanidins and vascular health. Nature 444 (7119), 2006, 566. doi:10.1038/444566a

[22] Leung L, Riutta T, Kotecha I, Rosser W. Chronic constipation: An evidence-based review. J Am Board Fam Med 24(4), 2011, 436-451

[23]. A. Scalbert, C. Manach, C. Morand, C. Rémésy and L. Jiménez Dietary polyphenols and the prevention of diseases. Crit Rev Food Sci Nutr. 45, 2005, 287-306.

[24]. B.A. Graf, P.E. Milbury and J.B. Blumberg. Flavonols, flavonones, flavanones and human health: Epidemological evidence. J Med Food. 8, 2005, 281-290 